\title{
El papel de los concejos en las Villas Ducales. Pleitos y paralización de programas artísticos
}

\author{
Esther Alegre Carvajal
}

\section{RESUMEN}

El fuerte desarrollo sufrido por la institución concejil a lo largo de la Baja Edad Media determinó que, en el siglo $x v 1$ cuando muchas de las villas realengas pasen a manos de la alta nobleza. sus Concejos presenten una

fuerte oposición ante su nueva situación. Esta resistencia concejil conseguirá que algunas de la villas vuelvan nuevamente a su condición de realengas, mientras que en muchas de

las que se mantienen bajo el poder señorial, los Concejos interpondrán

feroces pleitos por la actuación abusiva de sus nuevos señores. En villas como Pastrana, Béjar o Arcos de la Frontera. estos pleitos responden a las usurpaciones de terreno de la villa realizadas por los señores al poner en marcha sus programas arquitectónicos y urbanisticos destinados a crear en las nuevas cabeceras de sus Estados una Villa Ducal. En el caso de

Pastrana. el pleito interpuesto por el Concejo consiguió que el gran proyecto palacial diseñado por Alonso de Covarrubias para la Condesa de Mélito, no pudiera realizarse en toda su amplitud.

\section{ABSTRACT}

The strong developments suffered by the Council of Aldermen institution through the Lower Middle Ages, determined that when a large part of Royal Villas fell to the noblest aristocracy in the XvI century, the Town Councils offered strong opposition to this new situation. Due to this opposition. some villas reverted to their old royal-chartered status. Meanwhile, the Councils of the villas wich remained under their feudal Lord, engaged in ferocious lawsuits against the numerous abuses of their new Lords. In villas like Pastrana, Béjar or Arcos de la Frontera, these lawsuits refered to the usurpation of villas land by de Lord of de place, who wished to put into effec new urban planning and architectonic proyects designed to transforn these towns into Ducal Villas. In de case of Pastrana, the great palace designed by Alonso de Covarrubias for the Countess of Mélito, could not be implemented to its full extent, due to one of these lawsuits brought by the villa's Council against its Lord. 
Las Villas Ducales ${ }^{1}$ como tipología urbana, son una de las creaciones más brillantes del fructífero Renacimiento español. Estos conjuntos son producto de un largo desarrollo urbano histórico en el cual, de forma orgánica, se van a ir conformando una serie de importantes núcleos que, en la Edad Moderna, siglos XV, XVI e incluso XVII, van a ser adquiridos por un linaje nobiliario honrado con el título ducal, que va a realizar sobre ellos una serie continuada de actuaciones económicas, sociales y de prestigio, pero sobre todo, urbanísticas y arquitectónicas, dando como resultado esta tipología de ciudad específica y diferenciada.

Como núcleos urbanos ligados a Estados territoriales concretos, las Villas Ducales son la plasmación física del fenómeno de señoralización que se produce durante la Baja Edad Media, la imagen más efectiva del apropiamiento territorial que está realizando la nobleza, mediante el cual se consagra de forma inamovible su poder. En el continuo enfrentamiento que se desarrolla entre nobleza y monarquía a lo largo de todo este periodo, ambos estamentos van a tener que hacer concesiones sobre parcelas de poder para mantener otras prerrogativas; los grandes estados territoriales de la nobleza y sus cabeceras, las Villas Ducales, responden a esta lucha y a este intento de reajuste y reparto de privilegios entre ambos. En esta pugna, la nobleza, a cambio de reconocer la superioridad política de la Corona, consigue ingentes cesiones de territorio donde instaura estructurados y opulentos estados señoriales encabezados por conjuntos urbanos específicos y singulares, donde se concentra el poder y la representación y donde se plasma físicamente, ex novo, esta nueva tipología urbana, la Villa Ducal.

Este proceso hunde sus raíces en diversas circunstancias históricas. Por una parte, en la tendencia expansionista de la Baja Edad Media, con su considerable aumento económico y demográfico, el territorio se puebla de forma más regular y cohesionada lo que permite un mayor control sobre él y sobre zonas más extensas del mismo; las Villas se van constituyendo como núcleos intermedios dentro de la estructura jerarquizada de la organización territorial, hecho que implica ser centro, tarito emisor como receptor, de las actividades de una amplia comarca, así como poseer una administración municipal independiente y por tanto atenta a los problemas y la prosperidad de esa comunidad. Las ventajas de esta situación se

El estudio de las Villas Ducales españolas ha sido abordado en toda su extensión en ALEGRe CARvajal, Esther: Las Villas Ducales como tipología urbana. El ejemplo de la Villa Ducal de Pastrana. "Tesis Doctoral». Universidad Nacional de Educación a Distancia. Facultad de Geo. grafía e Historia. Departamento de Historia del Arte, 1999. 
ponen de manifiesto cuando son las propias aldeas las que luchan activamente para obtener el status de Villa, para conseguir lo que entonces se entendía y se nombraba como Privilegio de Villazgo, rango que era adquirido siempre por concesión real. A partir de este momento, las Villas se convierten en dueñas de su propio destino; reciben, normalmente también por privilegio real, concesiones de mercados y de terias, con lo que sentaban los cimientos, autogobierno y base económica, para iniciar un camino seguro de prosperidad. Las grandes Villas se transforman en centros funcionales de estructuradas comarcas, con una numerosa y estable población y una rica economía.

Por otra parte, la implantación de la dinastía Trastámara va a producir la ascensión de una emergente nueva nobleza que se va a hacer con todos los resortes del poder. Este proceso se concreta en la acumulación de Estados territoriales y de títulos nobiliarios, y en el reforzamiento de las estructuras de parentesco según el linaje. Todo ello lleva a la consolidación de una serie de familias nobiliarias vinculadas a un Estado señorial, nuevos linajes nobiliarios, fuertes, amplios y cohesionados, con conciencia de pertenecer a un mismo tronco, cuyos miembros se prestan protección y cuya riqueza material se protege mediante la institución del mayorazgo. El nombre del linaje estaba vinculado al topónimo del Señorio territorial originario de la familia, principal fuente de prestigio de sus miembros. Estos liriajes protagonizaron, durante todo el siglo $\mathrm{XV}$, una continua lucha entre las distintas ligas nobiliarias y contra la monarquía, en las que tuvieron importancia esencial las relaciones de parentesco de los mismos y sus redes clientelares. Todo este proceso culmina con el afianzamiento de esta potente nobleza que, como ya hemos dicho, se convierte en poseedora de una importante parte de la riqueza, sustentada en sus posesiones territoriales aseguradas por el vinculo del mayorazgo, cargada de mercedes nobiliarias y con una gran influencia política.

La nobleza, como centro de esta dinámica, va a conformar extensos Estados territoriales, como hemos indicado, base de su poder, que van a ser prestigiados con la concesión de la dignidad ducal, máxima dignidad nobiliaria, y sobre los que elegirán un centro urbano cabecera, normalmente el que da nombre al ducado, que podrán o no convertir en Villa Ducal.

En este proceso de acumulación de territorio, las grandes Villas medievales pasan a ser uno de los objetivos de codicia para estos nobles ansiosos de establecer Estados jurisdiccionales fuertes, en lo posible homogéneos y continuos, y con centros de poder en núcleos urbanos desarrollados. Esta dinámica histórica se traduce para estas Villas, en un elevado número de casos, en el abandono de su condición de realengas, 
para convertirse en parte de estos Estados nobiliarios, regidos por linajes que serán honrados con el título ducal. En esta época dejan de ser realengas Baena, Béjar, Gandía, Lerma, Medina de Rioseco, Madinaceli, Medina Sidonia, Olivares, Osuna, Sanlúcar de Barrameda, Zafra, Alba de Tormes, Arcos de la Frontera, Benavente y Cuéllar, entre otras. Los Duques adquieren, con la intención de fijar en ellas la cabeza, la capital de sus Estados nobiliarios, Villas ricas y dinámicas, con Concejos fuertes, desarrollados a lo largo de la Baja Edad Media, a las que van a potenciar hasta sus máximas consecuencias; las hacen capitales de sus Estados territoriales, instalan en ellas los instrumentos políticos y administrativos por ellos exigidos, desarrollan proyectos económicos que sirven de sustento material al nuevo Estado ducal y las convierten en la mejor imagen de la grandeza de su linaje, mediante el desarrollo de proyectos de prestigio y el establecimiento del palacio ducal en ellas. Todo esto altera profundamente el funcionamiento de estas Villas concejiles: muchas de sus antiguas instituciones son asfixiadas por las del nuevo Estado y, al tiempo que emergen las esplendorosas Villas Ducales, se produce una profunda decadencia de la vida municipal en ellas.

Pero el proceso de apropiación de estos codiciados, ricos y desarrollados centros urbanos no fue tan fácil como pudiera imaginarse: los entonces fuertes y consolidados Concejos y sus vigorosas sociedades se van a oponer frontalmente al proceso de señoralización en que se ven inmersos. Luchan por mantener su estatus realengo, e interponen pleitos contra las Casas ducales para mantener sus prerrogativas e influencia, ya que, pese al proceso comentado, los Concejos siguen siendo instituciones con gran poder, autonomia y autogobierno a lo largo de la mayor parte del siglo XVI, aunque a partir de su compra serán los señores los que fijen los términos de su actuación.

En primer lugar estas Villas van a desarrollar una oposición frontal al cambio que supone pasar a formar parte de un Estado nobiliario, abandonando la condición de realengo. Esta radical oposición determina que en algunas de ellas, la pretensión de los duques de convertirlas en capitales de sus Estados territoriales tenga que ser abandonada, y por tanto, que sus núcleos urbanos no inicien el proceso de transformación que los hubiera convertido en Villas Ducales, consiguiendo con ello mantener su condición primitiva de realengas.

Este es el caso de Trujillo, Villa que trataron de adquirir los Zúñiga al menos en dos ocasiones, teniendo que abandonar sus pretensiones en ambas, ante la oposición de los vecinos. En la primera ocasión, 1431, Don Pedro de Zúniga obtuvo, como compensación, el Señorio de Plasencia, 
con título condal. En la segunda ocasión, 1461, Don Álvaro de Zúñiga será compensado con la Villa de Arévalo honrada con el título ducal ${ }^{2}$. El Duque de Arévalo nunca llegó a tomar posesión de esta última, debido al rechazo permanente de sus habitantes a convertirse en sus vasallos. Sólo permanece cuatro años en posesión de los Zúñiga, ya que los continuos levantamientos populares hacen que la Reina Isabel la Católica valore su posición estratégica y anule su condición señorial revirtiendo su jurisdicción y territorio nuevamente a la Corona. Ante esta pérdida, la Reina premia a la familia Zúniga con el título ducal de Plasencia ${ }^{3}$. Sin embargo, en esta Villa los Zúñiga vuelven a encontrar una fortísima oposición popular con permanentes enfrentamientos. En 1488 se produce una sublevación, hecho aprovechado nuevamente por la Corona para hacerse con el control de tan importante enclave ${ }^{4}$, que tiene que ser abandonado por los Zúniga, aunque conservan el título ducal y reciben la dignidad del obispado de Plasencia, que recae reiteradamente sobre miembros de su linaje.

Todas estas circunstancias determinan que los Zúñiga se concentren en Béjar, su más antiguo Señorío jurisdiccional, y sea esta Villa la que se conviertan en la indiscutible cabeza de su Estado territorial y, con ello, en una auténtica Villa Ducal, por la acción continuada, sistemática y consciente de sus duques sobre ella. Años después, en 1485, se les honra con el Ducado de Béjar ${ }^{5}$.

De parecidas características son los casos de Fuenteovejuna o de Bélmez, ambos núcleos concedidos por Enrique IV a Don Pedro Girón. Anteriormente, habian forrnado parte de los señoríos del Maestre de Alcántara, Gutierre de Sotomayor, a partir de 1449 y 1450 . Pero Don Gutierre encontró dificultades para conservarlos en su poder e incluso tuvo que hacer frente, en 1453, a una sublevación en Fuenteovejuna, y no pudo conseguir que su sucesor en el Señorío ejerciera su dominio sobre las dos Villas. La

Título concedido por Enrique IV, por Real Cédula de 24 de abril de 1470. a Don Alvaro de Zuniga y Guzmán. Ricohombre de Castilla. II Conde de Plasencia, I Conde de Bañares, Justicia Mayor de Castilla y Administrador de la Orden de Alcántara.

Título concedido por los Reyes Católicos, por Real Cédula de 13 de abril de 1476, a Don Alvaro de Zúniga y Guzmán. Ricohombre de Castilla. Justicia Mayor de Castilla. Alcalde Mayor de Sevilla. I Duque de Arévalo. II Conde de Plasencia y Señor jurisdiccional de la Villa, II Conde de Ledesma, a quien en 1485 harian también I Duque de Béjar y I Conde de Bañares.

Plasencia era una de las grandes Villas, el centro comercial más próspero de la comarca, paso obligatorio de la ganaderia trashumante. que reportaba importantisimos beneficios, sede episcopal, y acceso al dominio de Extremadura.

Título concedido por los Reyes Católicos, por Real Cédula de 12 de octubre de 1485, a Don Álvaro de Zúniga y Guzmán. Ricohombre de Castilla. sobre su Señorio jurisdiccional de la Villa de Bejar. I Duque de Arévalo, I Duque de Plasencia, I Conde de Bañares, Justicia Mayor de Castilla y Administrador de la Orden de Alcántara. 
nueva señoralización de estos enclaves a favor de Don Pedro Girón no fue menos conflictiva, hasta el punto que el propio monarca en persona visitó Fuenteovejuna para instar a sus vecinos a que acatasen la merced hecha al Maestre ${ }^{6}$. Ante las claras dificultades para mantenerlas en su poder, Don Pedro Girón determina reconvertir de alguna manera el honor hecho por el rey e idea su permuta por Osuna y La Puebla de Cazalla. En esos momentos Osuna era la cabeza de la Encomienda de Calatrava, Villa en la que los Téllez Girón establecen la capitalidad de su Estado nobiliario y posteriormente son honrados con el título Ducal?

Otro caso reseñable es el de la Villa de Almonacid de Zorita, que Doña Ana de la Cerda, Condesa de Mélito, trató de adquirir en 1542 junto al resto de las posesiones Calatravas que habian formado parte de la Encomienda de Zorita y con las que trataba de establecer un Estado nobiliario con cabecera en Pastrana. La Villa de Almonacid alegó antiguos privilegios reales que impedian su señoralización ${ }^{8}$ y que la mantuvieron en su condición de realenga. Posteriormente, cuando Ruy Gómez de Silva, Príncipe de Éboli, compra el Señorío de Pastrana en 1562, trata nuevamente de adquirir la Villa de Almonacid para integrarla a su Estado territorial, sin conseguirlo.

En esta misma línea de oposición de los Concejos a entrar en la nueva condición de Señorio, se desarrollan las intensas tentativas llevadas a cabo por la Villa de Pastrana para lograr su autocompra ${ }^{9}$. Es decir, cuando por orden del Emperador Carlos la Villa de Pastrana es segregada de la Orden Militar de Calatrava y puesta a la venta, el Concejo interpuso urgentes oficios en la Corte, a través de su procurador general, Juan Clavete, enviado a ella especialmente por un grupo de treinta vecinos, los más ricos de la Villa, que intentaron hacer una oferta para la autocompra, gestión con la que no se obtuvo resultados positivos, por el evidente beneficio

Cabrera Muñoz, Emilio: «De Osuna a Fuenteovejuna. La transformación en señorío de una antigua Encomienda Mayor de Calatrava", en Osuna entre los tiempos medievales y modernos (siglos x(I-xyII). Ayuntamiento de Osuna-Universidad de Sevilla, 1995, págs. 56-57.

El Título de Duque de Osuna fue concedido por Felipe II, por Real Cédula de 5 de Octubre de 1562, a Don Pedro Téllez Girón y de la Cueva, Ricohombre de Castilla y Grande Inmemorial, V Conde de Ureña. Señor de la Villas de Osuna, Peñafiel, Olvera, Cazalla. Archidona, Notario Mayor de Castilla, Camarero Mayor de Felipe II, Consejero de Estado, Virrey y Capitán General de Nápoles. El primer Duque de Osuna vivió entre 1494 y 1558. fundó la iglesia Colegial de Osuna y la Universidad, dotándolas espléndidamente.

8 Escudero de COBEnA, Matías: Relación de casos notables, ocurridos en la Alcarria y otros lugares en el siglo xvı, escrita por el cronista de Almonacid de Zorita. Guadalajara, Ayuntamiento de Almonacid de Zorita, 1982.

y Prieto Bernabe, José Manuel: La venta de la Jurisdicción de Pastrana en 154i. Madrid. CSIC, 1986 . 
El papel de los concejos en las Villas Ducales. Pleitos y paralización...

económico que esperaba obtener la Hacienda real con esta venta que se consumó en 1541. Fue adquirida por Doña Ana de la Cerda, Condesa de Mélito.

Una vez que estas ricas y orgullosas villas entran a formar parte de los Estados nobiliarios, pese a su resistencia inicial a ello como hemos indicado anteriormente, todavía a lo largo del siglo XVI, sus Concejos mantienen parte de su solidez y de su independencia, y tratan de defenderse de lo que consideran abusos por parte de sus nuevos Señores. Son abundantes los pleitos presentados por estos Concejos debido a las actuaciones ducales en las villas, muestra de la fortaleza y del vigor de estas instituciones.

Dirigidos a parar los abusos de sus señores, los Téllez Girón, son, continuos y de una extraordinaria dureza, los pleitos interpuestos por los Concejos de las Villas de Osuna, Morón o Fregenal de la Sierra, pertenecientes al Estado de Osuna. Las actuaciones de los tres primeros Condes van a estar dirigidas al intervencionismo en el gobierno municipal, al aumento del impuesto de alcabalas, al desarrollo y control del monopolio sobre hornos y molinos, a la usurpación de bienes de propios, a la apropiación ilegal de tierras, del uso de montes, bosques, caza y pesca de forma abusiva, etc. Aunque la actuación de los tres titulares va a ser parecida, la mayoría de los conflictos se inician durante el gobierno de Don Juan, II Conde, y se empiezan a solucionar a partir de 1539 , fecha en que se produce una de las primeras sentencias de la Chancillería de Valladolid ${ }^{10}$. De caracteristicas parecidas es el pleito seguido por el Concejo de Arcos de la Frontera, en 1544, contra sus Duques, por la usurpación que éstos habian hecho de tierras de propios.

Pero más interesantes van a ser otra serie de pleitos relacionados con las actuaciones ducales, pero que están motivados por los programas constructivos desarrollados por los duques, destinados a conseguir y a ejecutar las reformas urbanas y arquitectónicas que los van a convertir en Villas Ducales.

Una de las características que define la tipología urbana de Villa Ducal es la presencia en estos núcleos de un área nobiliaria de calidad constituida, fundamentalmente, por el conjunto urbanístico palacio-plaza representativa como espacio de prestigio y exhibición aristocrática.

En los antiguos y apiñados núcleos medievales la consecución de este espacio por parte de los Duques va a ser otro de los grandes motivos de

10 Viña Brito, Ana: Morón y Osuna en la Baja Edad Media. Universidad de Sevilla, Ed. Gráficas Sol, 1991. págs. 189-224. 
enfrentamiento con los Concejos y sus Villas, y fuente de importantes pleitos, que en algún caso llegan a alterar los planes urbanísticos previstos.

Un ejemplo característico de este tipo de pleitos es el interpuesto por el Concejo de Béjar, en 1555, contra la Duquesa Doña Teresa. Béjar ${ }^{11}$ es un tipo paradigmático de Villa Ducal en la que la consecución de un espacio de prestigio, área nobiliaria, se va a conseguir a través de la transformación del castillo en palacio y de la reutilización como plazas públicas de los espacios libres intramuros, de origen medieval, anexos al castillo y a la puerta de la Villa. Esta transformación se realiza paulatinamente a lo largo de los siglos y de las sucesivas actuaciones de los Zúñiga.

Las primeras obras de remodelación de la antigua fortaleza las lleva a cabo el segundo Zúñiga dueño de Béjar, Don Pedro, pero éstas son de pequeño alcance. Es con Doña Teresa ${ }^{12}$, a partir de 1533, año en que se hace efectivo su gobierno, cuando se inician obras de una mayor envergadura que se concretan en la remodelación de parte de las estancias interiores y la construcción de una galería y unos jardines. La construcción de estos jardines justifica una de las quejas más importantes del Concejo en el pleito interpuesto contra la Casa Ducal, «...construir una fuente en su palacio para regar los jardines del mismo dejando sin agua a uno de los barrios...» ${ }^{13}$. Éste era el jardín y huerta situados al mediodia y que, pese a las quejas, fueron construidos por Doña Teresa. Pero el Concejo se quejaba igualmente de que la Duquesa se había adueñado de un espacio contiguo al castillo y a la puerta de la Villa que era propiedad de los vecinos. En ambos espacios la Duquesa tenía el proyecto de construir unos jardines, pero debido al pleito del Concejo sólo se pudieron realizar los situados a mediodía, jardines acompañados de una rica huerta que requería el agua usurpada a la Villa. Sin embargo, el jardín secreto a la italiana proyectado en el norte se paralizó, aunque el terreno no fue devuelto a los vecinos. Este proyecto fue retomado durante el gobierno del Duque Don Francisco que, además de continuar las obras de transfor-

\footnotetext{
13-44.

Alegre Carvajal, Esther: "La Villa Ducal de Béjar”. Béjar, Estudios Bejaranos, 1998, págs.

Doña Teresa de Zúñiga y Guzmán heredó el Ducado de su tío Don Álvaro de Zúñiga y Guzmán, II Duque de Béjar, que gobernó hasta 1531. Éste se casó con Doña Maria. su tía, sin que el matrimonio tuviera descendencia. por lo que el mayorazgo recayó en la primogénita de su hermano Francisco, doña Teresa. Tomó posesión en 1531, pero surgieron tantos problemas en la Villa que tuvo que dejar como Duquesa-gobernadora a su tia Dona María, hasta 1533, año de su fallecimiento.

Muñoz Dominguez, José: «Naturaleza versus artificio. El Monte. El Bosque y otros jardines Bejaranos del siglo xvl.. en El Bosque de Bejar y la Villa de recreo del Renacimiento. Actas de las Il jornadas, Béjar. 1997. págs. 49-93, pág. 60
} 
mación del viejo castillo dentro de un estilo palaciego, con la construcción del patio central en un riguroso estilo renacentista, la reforma de la fachada norte, la construcción de un nuevo ala y la mejora de las entradas al conjunto fortificado, ideó la denominada Huerta del Aire, pequeño jardín secreto renacentista que ocupaba el espacio causante de las disputas con la Villa. Estas obras fueron dirigidas por Pedro Marquina ${ }^{14}$, uno de los discípulos de Rodrigo Gil de Hontañón, que se encontraba trabajando en la catedral de Plasencia, aunque no se conoce de quien son las trazas del patio ni las del jardín.

Un caso de parecidas características es el que se desarrolla en Arcos de la Frontera, donde en 1544 el Concejo de la Villa interpone un pleito contra sus Duques, tal y como hemos indicado anteriormente, por la usurpación que éstos habían hecho de terrenos de propios, además de por las transformaciones que pretendían llevar a cabo en la actual Plaza Mayor, en ese momento patio de armas del castillo. Presumiblemente, la actuación de los Duques que desató las iras del Concejo, fue el apropiamiento de terreno perteneciente a la Villa, tal y como habia ocurrido en Béjar. Finalmente el proyecto ducal no prosperó, y aunque no sabemos exactamente la causa, podemos intuir que una parte de la responsabilidad la tuvo el pleito con el Concejo.

Sin duda, el enfrentamiento y el pleito más significativo y más virulento, en este sentido, es el que se desarrolla entre el Concejo de Pastrana y la Condesa de Mélito, Doña Ana de la Cerda. Enfrentamiento radical que tiene una trascendencia fundamental ya que impide la realización completa del complejo palacial proyectado por Alonso de Covarrubias para Doña Ana ${ }^{15}$.

La Condesa de Mélito adquiere la Villa de Pastrana mediante compra a la Corona, en el año 1541. Desde ese mismo momento inicia la construcción de los símbolos de su Señorío. Siguiendo la rica e innovadora tradición renacentista de las Villas Ducales, idea la construcción de un área palacial, conjunto urbanistico en el que se unen palacio y plaza representativa.

La Condesa encarga su proyecto al arquitecto Alonso de Covarrubias ${ }^{16}$. Este artista estuvo muy vinculado a la familia Mendoza y a las tierras de Guadalajara, hechos determinantes para que fuera escogido por la

\footnotetext{
14 Ibidem, pág. 60.

15. Alegre Carvajal. Esther: La Villa Ducal de Pastrana. Guadalajara. AaCHE Ediciones. 2003.

16 Garcia López, Aurelio: “Alonso de Covarrubias, autor del palacio Ducal de Pastrana (Docu mentación sobre su construcción, de 1542 a 1553)". Guadalajara, Wad-Al-Hayara, Institución Pro vincial de Cultura "Marqués de Santillana". Diputación de Guadalajara, 1992. n. 19. págs. $51-74$
} 


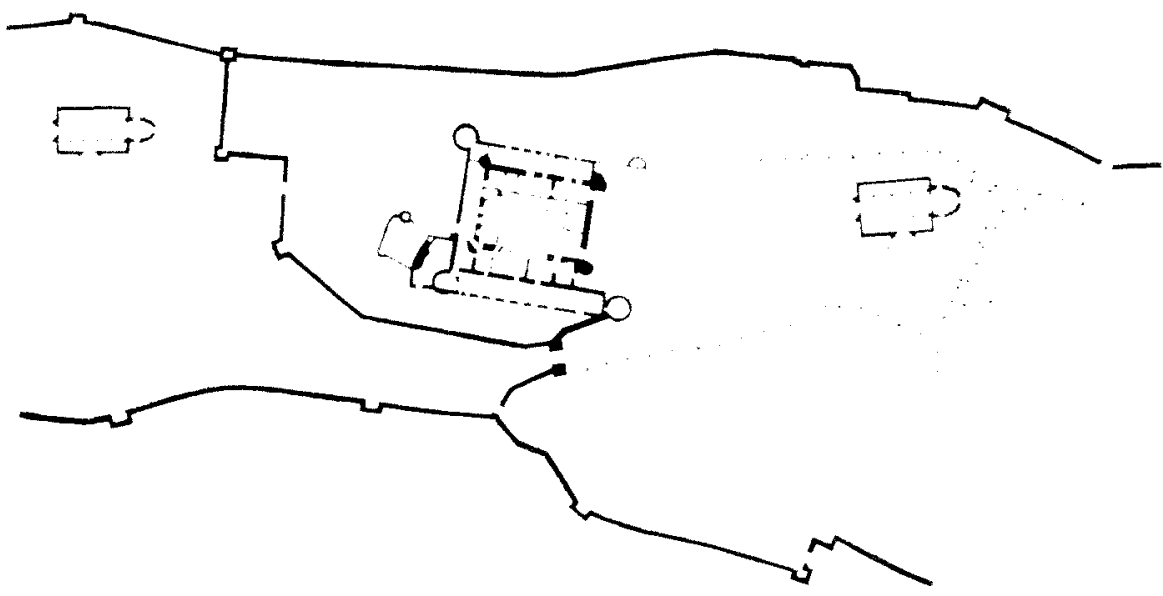

Fig. 1. Conjunto palacial de Béjar tras las actuaciones de los Zúniga.

Condesa de Mélito para llevar a cabo las transformaciones en Pastrana; para ella ya había trabajado en Toledo además de haberlo hecho de forma independiente en Pastrana en la construcción del retablo de la iglesia ${ }^{17}$.

En Pastrana Covarrubias ensaya una nueva aportación al Renacimiento español: no sólo diseña una casa-palacio, sino que integra este edificio

Archivo Parroquial de Pastrana (APP), Libros de Fábrica. 1536. sin foliar. ... Yten se le res. ciben en cuenta al dicho Antonio Garcia Redondo mayordomo ochenta y cinco mil maravedis que parescio haber pagado a Juan de Borgona y a Alonso de Covarrubias de la obra de talla. pintura y oro del retablo de la dicha iglesia con los cuales se les acabaron de pagar las doscientas y cincuenta y cinco mil maravedis que ovieren de haber de la obligación y relación de la dicha obra como parescio por nuestra carta de pago e finiquito firmado de sus nombres que quedo en poder del dicho mayordomo e señalada.

Yten doce mil e quinientos maravedies que pago a Juan de Borgoña y a Alonso de Covarrubias por las demasias que hicieron en la obra del dicho retablo de mas de lo que eran obligados como parescio por una carta e finiquito firmada de sus nombres que quedo en poder del dicho mayordomo señalado.

Yten ocho mil y once maravedis que parescio por dos cartas de pago haber pagado a Juan de Borgoña y a Alonso de Covarrubias y por la talla y madera de seis filateras que se hicieron para la iglesia y del oro y asentallas... 


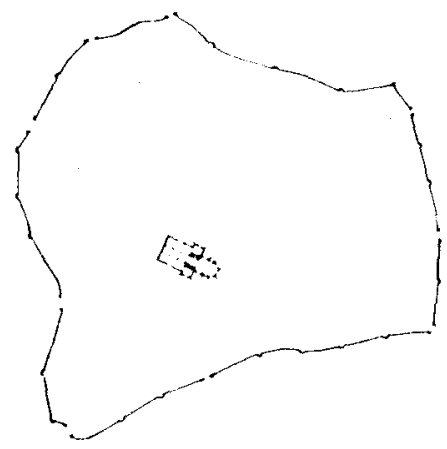

Fig. 2. Pastrana a principios del siglo XVI, antes de la compra del señorio por la Condesa de Mélito.

en un proyecto global ${ }^{18}$. Dispone un área de prestigio, representativa y señorial, complejo que se compondrá de un palacio renacentista, precedido de una gran explanada que confería una amplia perspectiva a la fachada del edificio que lo presidía, todo ello delimitado por una muralla monumental planteada como continuación de la cerca medieval de la Villa, de tal forma que la plaza quedaba definida también como el elemento de unión entre el casco urbano medieval y la zona señorial renacentista, sin solución de continuidad. El acceso al conjunto se realizaba a través de una puerta monumental diseñada por el propio Covarrubias y Luis de Vega. Todo el programa se completaba con unos jardines abiertos a la fachada y como continuación de la misma, en los laterales y en la parte posterior del palacio, quedando delimitados por la muralla proyectada. Covarrubias concibe el proyecto dentro de un riguroso sometimiento del espacio a la geometría, disponiendo un eje axial que ordena simétricamente el conjunto, a la vez que establece un doble eje de perspectiva visual, el

18 Alegre Carvajal, Esther: Op. cit., págs. 636-656. 
primero define la fachada del palacio como emisor de vistas desde la gran plaza y el otro articula el jardín en diferentes niveles, serie escalonada y rítmica de balaustradas, escaleras y terrazas-mirador, que le convierten en un excelente receptor de vistas sobre la plaza como paso hacia el paisaje circundante.

La falta de espacio suficiente dentro del recinto urbano, hizo que se eligiera para su ubicación una zona aneja a la muralla medieval, en su lado de saliente, pero fuera de ella; sólo alli era posible desarrollar un proyecto de esta amplitud.

Desde el mismo momento de la toma de posesión de la Villa, en enero de 1542, Doña Ana inicia la construcción del palacio, adosado a la cerca medieval, y la habilitación de la explanada delantera como plaza, obras que van a motivar el disgusto del Concejo. La actuación abusiva de Doña Ana incita la reacción airada del Concejo que, en 1546, interpondrá un pleito ${ }^{19}$ contra la Señora en el que entre otras muchas cosas se manifiesta el ambiente enrarecido que se vivia en Pastrana desde su señoraliza-

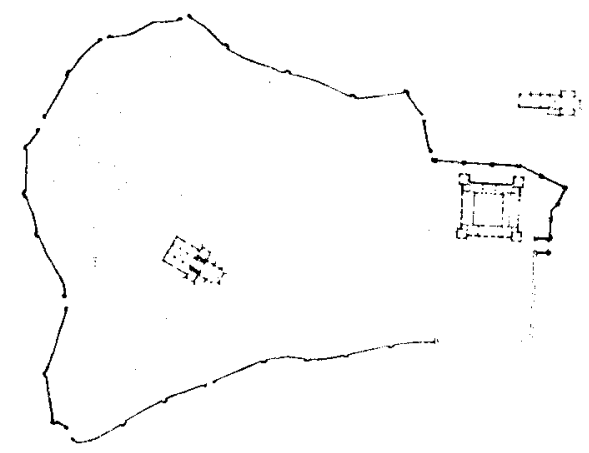

Fig. 3. Pastrana con el conjunto palacial proyectado por Alonso de Covarrubias.

19 Archivo Municipal de Pastrana, AMP, sig. PER-4. 
ción. El Concejo se quejaba de que los justicias de Doña Ana y su hijo Don Gastón de la Cerda se dedicaron a molestar sistemáticamente a los vecinos, a sus autoridades concejiles, y a todos cuantos se encontraban por la calle. Doña Ana llegaba a molestarles y vejarles personalmente haziendoles ynjurias y diciendoles malas palabras y otras afrentas. Sin embargo, fue el acondicionamiento de la plaza delantera del palacio, lo que finalmente desató las iras del Concejo al producirse, además, el derribo de una parte de la cerca medieval de la Villa. El proyecto era una obra de envergadura, el terreno en pendiente elegido requería importantes movimientos de tierra, un costoso desmonte en la zona donde se tenía que construir el palacio y un relleno en el lugar de la plaza delantera al mismo.

Toda la época del gobierno de Doña Ana va a estar marcada por estos dos hechos, la construcción del complejo palacial y el pleito que la enfrentó con el Concejo por ello, tal y como vamos a ir analizando.

En 1546, cuando las obras del palacio ya se habian iniciado y en algunos aspectos debian estar muy avanzadas y cuando se produce el derribo de la cerca medieval de la Villa, el Concejo, como hemos indicado, interpone un pleito contra la Señora en el cual la acusa, ante la Chancillería de Valladolid, de usurpar tierras concejiles, talar árboles y construir caleras en los bosques comunales, destinados a las construcciones señoriales, pero sobre todo haber derribado una parte de la cerca que ...es propia de la villa... y estar construyendo una ...casa fuerte... en ella.

La polémica y el enfrentamiento más fuerte, como vemos, se centró en dos elementos importantes de la ciudad: por una parte la oposición a la construcción de una casa-fuerte, por otra el requerimiento de reconstrucción de la parte de la cerca que se había derribado. Estos dos elementos, castillo y muralla, simbolizaban visiones opuestas de la libertad ciudadana. La muralla que rodeaba la ciudad constituía un sistema de defensa mucho más antiguo y popular que el castillo, ya que delimitaba el espacio de desarrollo de los derechos de los ciudadanos y su comunidad de intereses, mientras que el castillo se entendía como un símbolo visible de sometimiento y vasallaje ${ }^{20}$.

Desde 1546 y hasta la resolución del pleito las obras de la casa fuerte se paralizan, pese a que en algunos aspectos debian de estar muy avanzadas; al menos, se habría realizado ya todo el acondicionamiento del terreno, el desmonte y el relleno en la zona de la plaza, así como se habrian

20 MorRIS. A.E.J.: Historia de la forma urbana. Desde sus origenes hasta la revolución industrial. Barcelona, GG,1984, pág. 106. 
construido elementos importantes del palacio, la fachada principal, la portada, el zaguán y el cuerpo noble del edificio, quedando la parte posterior $y$ los jardines sin realizar.

El Concejo se opuso a la construcción de la casa fuerte de la Señora, tal y como la calificaban, alegando que la construcción estaba prohibida por las leyes del Reino y se levantaba sin licencia del Emperador ...estando prohivido por las leyes e premáticas de nuestros reynos que no se pudiesen hazer fortalezas ni cassas fuertes sin licencia nuestra agora nuevamente la parte contraria (Doña Ana) avia hecho e hazía una fortaleza en la dicha Villa sin licencia como era necesario..., asi como que la obra que se empezaba a levantar se había proyectado a ocho o diez pasos de la Villa y no a los cuatrocientos pasos que habian sido especificados en la Carta de venta. Pero aunque éste fue uno de los puntos más virulentos del enfrentamiento, no fue el detonante, puesto que la obra llevaba iniciada varios años, sino el agravio de que se hubiera tirado una parte de la cerca de la Villa.

En realidad, la mayor parte de las protestas argumentadas, primero por el Concejo y posteriormente, tras la primera sentencia de la Audiencia en las apelaciones, por el Común de Zorita, iban encaminadas a impedir el proyecto de construcción de una fortaleza calificada de innecesaria e ilegal, origen, según ellos, de un gran ...daño y perjuizio..., no sólo para el pueblo sino también para toda la comarca de Zorita. Pero el Rey Carlos $V$ había vendido el Señorío de Pastrana expresamente con la concesión de licencia para la construcción de una casa-fuerte. El interés que Carlos $V$ tenía en permitir levantar estas fortalezas o casas-fuertes a los nobles no era otro que el económico, sin que hubiera en ello ningún tipo de intencionalidad militar. Por lo tanto, para que Doña Ana pudiera levantar su palacio, tuvo que aceptar un precio más alto en la compra del Señorío. En este sentido, las quejas del Concejo tenían difícil justificación, ya que en la Carta de venta el Emperador permitía que se hiciera la dicha casa-fuerte. A pesar de ello, el Concejo de Pastrana continuó arremetiendo contra esta construcción, alegando que la obra se tenia que hacer a cuatrocientos pasos alejada de la Villa y no inmediata a ella como se estaba realizando, por lo que solicitaba que las obras se suspendieran indefinidamente aunque tuvieran todas las licencias y permisos oportunos. El que se realizara tan cerca del núcleo, señaló el Concejo, les había llenado de temores y miedos. En ese momento, los Concejos veían en las fortalezas, en lugar de una eficaz protección en tiempo de guerra, una continua amenaza durante la paz, no olvidemos que el episodio de la guerra de las Comunidades estaba todavía muy cercano.

Por otra parte, el Concejo de Pastrana consideraba ilegal el tipo de construcción que se tenía proyectado, pues si bien la licencia del Empe- 
rador permitía hacer una casa fuerte, ésta tendría que ser ordinaria y no tan fortificada ...que sería si se acabase de hazer una de las más fuertes del Reyno... Frente a todas estas acusaciones el procurador de la Condesa alegaba que la casa-fuerte no perjudicaria en nada a los vecinos del pueblo.

Junto a la casa-fuerte, como hemos señalado, fue la muralla el otro elemento por el que Concejo y Señora se enfrentaron violentamente. Por una parte, durante las obras realizadas se había derribado un lienzo de la muralla medieval, hecho que como hemos señalado fue el auténtico detonante del pleito. Por otro lado, el proyecto de Covarrubias incluia la construcción de una nueva muralla que rodeaba el conjunto palacial. Tanto el derribo de la cerca antigua como la construcción de la nueva muralla fueron motivo de enfrentamiento.

La pretensión de la Señora era hacer ... Quinientos pies de muralla en lo largo y de ocho pies en ancho y de alto más de quarenta pies, y con muchos cubos muy espesos, siendo antes de cien pies en largo y çinco de ancho solamente. lo cual todo hiciere para fortalezer la dicha Villa y çerca, y en provecho y utilidad della y de la frotaleza, como constaba notoriamente por bista de ojos... Con la nueva muralla se pretendía encerrar el palacio y la plaza proyectados, y que el conjunto palacial quedara integrado como una parte más de la Villa; con el derribo de la cerca antigua se quería conseguir la integración de la nueva zona nobiliaria con el casco medieval.

A lo que el Concejo alegaba ...E proque el muro o çerca que la dicha Doña Ana dezia que queri hazer, en lugar de los muros de la dicha Villa, hera por desviada parte e lugar que los que adelante estavan y para cercar su fortaleza, y no para provecho de la dicha Villa. E ya que la dicha Condesa los hiziese por la parte e lugar que dezia, eran de ningún provecho para la dicha Villa, porque junto con la parte do los queria hazer estava una cuesta alta que sobrepujaba la dicha Villa...

A lo que el procurador de la Condesa respondía ... E porque lo que la dicha su parte derribara fuera un pedaço de çerca muy pequeño, que es taba hecho de piedra e barro, y estaba para se caer; e porque la dicha su parte derrocaba el dicho pedaço de cerca no fuera para que la dicha Villa quedase abierta, sino para lo hazer en otra parte de muy buena canteria y muy costoso, e que la villa quedase çerrada muy mejor, como lo tenia començado a hazer...

Expresándose igualmente la intención de mejora y adorno de la ciudad, defendida por todos los tratadistas de la época ...E porque lo que la dicha su parte queria hazer hera en gran pro e utilidad de la dicha Villa $y$ del hornato de ella, porque yendo la çerca por donde la dicha su parte la 
avia començado a hazer dentro de la Villa quedava una plaça muy grande e muy nesçesaria para la dicha Villa y hornato de ella...

Esta muralla no se pudo construir debido a la sentencia dada por la Audiencia favorable a la reconstrucción de la cerca antigua por el mismo sitio donde se había derribado. De esta forma, el conjunto palacial no quedó integrado como una parte más de la Villa, sino diferenciado y apartado de ella a pesar de su proximidad. Aunque, tal y como señaló el procurador de Doña Ana, la nueva muralla ya se había comenzado a hacer antes de que se diera la sentencia de la Chancilleria y que el plan tuviera que ser paralizado; $y$ de hecho, en la esquina derecha de la plaza existe un gran cubo que pudo ser una de las partes construidas.

Este enfrentamiento pone de manifiesto, como ya hemos comentado, la función simbólica que los edificios de una ciudad podían tener, y resulta altamente significativo porque es un ejemplo paradigmático del traspaso de poder que se estaba produciendo en toda Castilla: la pérdida de libertad y de peso específico de los Concejos frente al cada vez más agresivo proceso de señoralización.

Otro de los elementos del conjunto palacial que se vio directamente afectado por el pleito del Concejo fue el jardín ${ }^{21}$. En todo el conjunto proyectado por Covarrubias, la característica fundamental es el sometimiento del espacio a la geometría, estableciéndose un eje axial que ordena todos los elementos tanto en la fachada como en el interior. Los jardines se disponen siguiendo este mismo esquema, de forma simétrica a un lado y otro del eje que ordena el conjunto, en perfecta coordinación con el edificio al que acompañan y componiéndose desde ellos uno de los ejes de perspectiva visual. El terreno en pendiente permitió jugar con la propia topografía existente. El jardín se dispuso en las fachadas laterales y en la parte posterior del palacio. A un lado y otro del edificio y continuando la línea de la fachada principal del mismo, se proyectaron dos jardines cerrados, limitados por muros su espacio regular, como los jardines secretos a la italiana, tan de moda entre la nobleza española.

Pero este jardín simétrico, tal como estaba proyectado, y debido a la proximidad del palacio a la Villa, necesitaba ocupar una parte de terreno de ésta, que se podía conseguir al derribar todo el lienzo de cerca que lindaba con la nueva construcción e incorporando el espacio tomado por ella más la zona

21 El estudio del jardín proyectado por Covarrubias, así como una reconstrucción ideal del mismo se puede consultar en Alegre Carvajal, Esther, Nieto Taberne, Tomás: Los jardines de Pastrana. Guadalajara, AACHE Ediciones, 1997. 


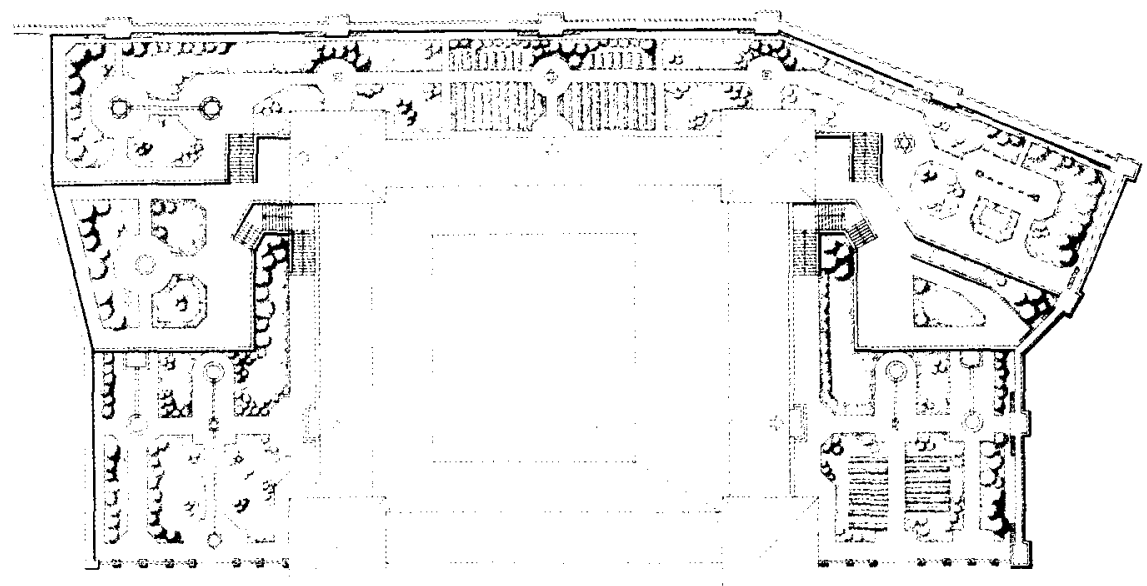

Fig. 4. Reconstrucción ideal de jardín proyectado por Alonso de Covarrubias.

libre aneja al mismo, una parte del caserío no ocupada por la edificación. Éste fue el motivo por el que tuvo que ser derribada la muralla medieval. Covarrubias habia proyectado eliminar el lienzo de muralla derribado para conseguir con ello dos objetivos, la integración del conjunto palacial con la Villa y obtener el terreno suficiente para poder desarrollar el jardín proyectado.

Con este jardín Covarrubias pretendía cerrar todo un proyecto de conjunto basado en la idea de representación señorial, dominado por la axialidad y la geometría y disponiendo dos ejes de perspectiva visual distintos, el de la plaza hacia el palacio, y el de los miradores del jardín hacia la plaza y el paisaje. Adopta una configuración totalmente arquitectónica, armónica con el desarrollo del edificio.

El pleito y la paralización de las obras desde 1546 hasta 1549 mantuvieron esta zona lateral del palacio en contacto con la Villa medieval, en una indefinición que provoca un gran retraso en la realización del proyecto; dada la segunda sentencia de la Audiencia, la obligación de reconstruir la cerca por parte de la señora impidió el desarrollo de esta zona de jardín; la primera terraza no podía tener una extensión suficiente como para albergar en ella un jardín secreto al igual que el de su lado opuesto, eliminándose el enlace de esta terraza con las superiores. Sin embargo, los muros de contención de tierras, necesarios, fueron construidos con una disposición idéntica a los de su lado opuesto; con ellos sí pudo ser realizada la terraza superior, prácticamente con toda la extensión que se había ideado. 


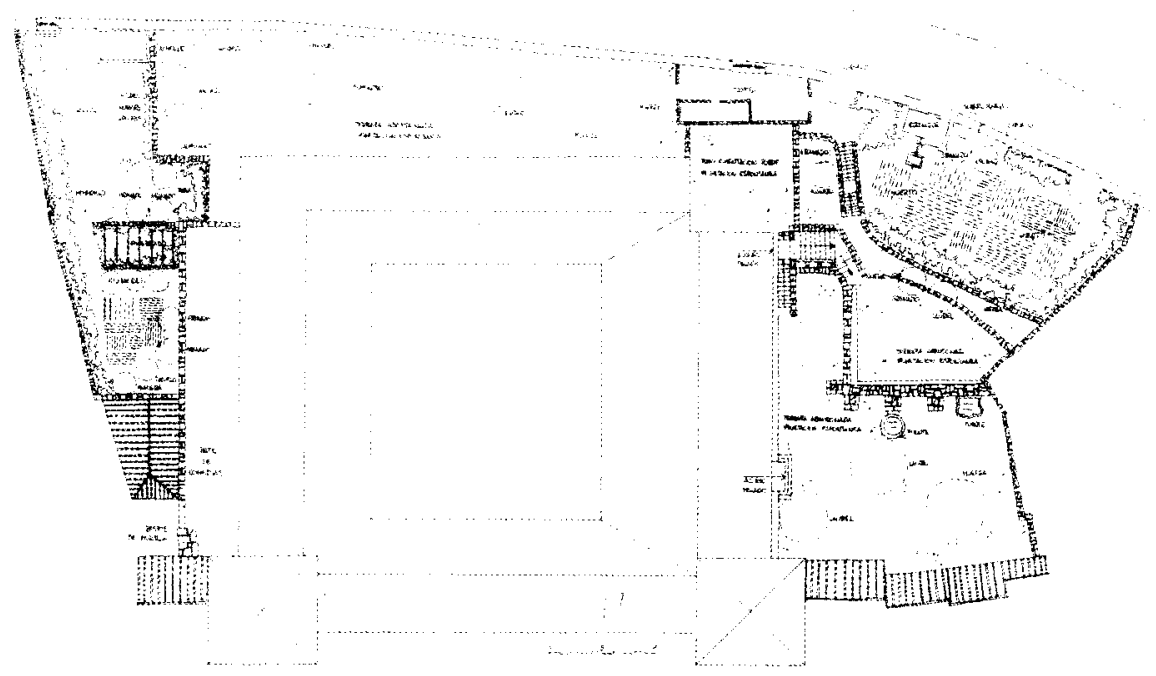

Fig. 5. Desarrollo del jardín que se realizó en el palacio de Pastrana.

En 1549 las obras del palacio se pudieron reanudar gracias a la sentencia dictada por la Audiencia que permitía la construcción de la casa-fuerte. Pero las alegaciones continuaron, ahora presentadas por el Común de Zorita, ya que por su parte el Concejo consideró que no se había tenido en cuenta el tema de la casa fuerte cuya construcción se permitía y el derribo de la muralla, sobre la cual la Audiencia no se pronunciaba; por su parte la Condesa de Mélito juzgó que la condena había sido desfavorable a su causa. Las nuevas alegaciones determinaron una nueva paralización de las obras.

Las etapas de construcción del palacio coinciden plenamente con las etapas de desarrollo del pleito sostenido por el Concejo y la Condesa, y con las diferentes resoluciones tomadas por la Audiencia. Las trazas del conjunto fueron encargadas en 1541, en 1542 ya estaba realizado el proyecto y en 1544 había comenzado el acondicionamiento del terreno y la construcción del edificio. En 1546, con motivo de los pleitos, se paralizaron las obras. En 1548 la Condesa contrata nuevos maestros de obras ${ }^{22}$ y

22 Alegre Carvajal, Esther: Op. cit., págs. 703-706. En la primera etapa de la construcción del edificio, de 1544 a 1546, la dirección de obras fue realizada por Martín de lbarra, maestro montanés, presumiblemente recomendado para esta construcción por el propio Covarrubias, ya que no se constata que trabajara anteriormente en esta zona, sino que parece más probable pen- 
nuevos materiales desplegando una actividad que indica que esperaba una rápida y favorable sentencia de la Audiencia, hecho que se produjo en 1549. A partir de ese año las obras se reanudan por un corto espacio de tiempo, con gran eficacia; en esta nueva etapa se terminó el edificio, a pesar de quedar el patio sin finalizar, y se concluyó la estructura de la gran plaza delantera. En 1552 se inicia la tercera etapa de construcción del palacio; la Audiencia vuelve a dictar sentencia, esta vez claramente desfavorable a la Condesa, obligándola a reedificar el trozo de la cerca que habia tirado, aunque se le permitía la construcción de su palacio.

...La dicha condesa torne a hazer a su costa la dicha cerca que ansi derribó, la cual comiençe a hazer luego que fuere requerida con la carta executoria de esta nuestra sentencia, y la acabe dentro de un año, segun e de la forma e manera que estaba al tiempo que la derribo...

El pleito interpuesto por el Concejo de Pastrana contra Doña Ana impidió que el proyecto global de Covarrubias se llevara a término, dejando el palacio sin terminar y malogrando la finalización del proyecto de conjunto: no se construyeron las torres traseras, el patio y la escalera, dejó sin construir la muralla proyectada, redujo la monumentalidad de la puerta de entrada, y condicionó de forma determinante la disposición del jardín. Aunque del proyecto original se realizaron los elementos más importantes, el palacio con sus jardines en parte, y la plaza como lonja anterior al mismo. La muralla no fue construida más que en las zonas en que fue absolutamente necesaria como muro de contención de tierras, es decir, en los laterales y frente de la plaza, y la puerta monumental de entrada al conjunto se simplificó notablemente por falta de presupuesto.

\footnotetext{
sar que vino desde la Corte reçomendado por el arquitecto. A él se debe el replanteo de una gran parte de la fachada y del cuerpo principal del palacio, pero sobre todo, las importantísimas obras de acondicionamiento del terreno que hubo que realizar para el desarrollo del proyecto. Tras la suspensión del trabajo durante los años del pleito, el maestro de obras lbarra ya no se encontraba en Pastrana, por lo que al reanudarse éstas nuevamente, tanto la Condesa como el propio Covarrubias optaron por llamar a maestros de obras conocidos por estar relacionados con trabajos realizados por los Mendoza, al tiempo que eran naturales de la zona. Así, desde 1548, aunque las obras no estaban oficialmente reanudadas en espera de la resolución de la Audiencia, se estaba trabajando en las murallas; en ellas lo hacen desde ese 1548 el maestro de obras $\mathrm{Ni}$ colás de Adonza, que tenía su residencia habitual en Mondéjar, y donde había dirigido las importantes obras de la iglesia parroquial encargadas por el Marqués de Mondéjar, y los hermanos Juan y Pedro del Mazo. Nicolás de Adonza estuvo trabajando hasta 1552, y es seguro que a su mano se debe una parte importante de la portada. Las obras de madera de los artesonados se iniciaron, igualmente, a partir de 1548; fueron encargadas a Justo de Vega y Cristóbal de Nieva, traldos de Madrid por Covarrubias, artesanos de gran prestigio que ya habian trabajado anteriormente con el arquitecto en el proyecto del gran Alcázar real madrileño. A ellos se debe la talla de los artesonados platerescos de las salas principales.
} 
Del jardín quedó sin resolver el lado situado en el lateral de poniente, lo que confirma que Doña Ana cumplió la orden de la Audiencia y reedificó el trozo de muralla que había derribado, aunque no como muralla sino como simple muro de cerramiento del propio jardín, tal y como hemos explicado. El pleito había mantenido esta zona en una indefinición que provoca un gran retraso en la realización del proyecto; dada la sentencia, la obligación de reconstruir la cerca impidió el desarrollo de esta zona de jardín; la primera terraza no podía tener una extensión suficiente como para albergar en ella un jardín secreto al igual que el de su lado opuesto, eliminándose el enlace de esta terraza con las superiores. Sin embargo, los muros de contención de tierras, necesarios, fueron construidos con una disposición idéntica a los de su lado opuesto; con ellos sí pudo ser realizada la terraza superior, prácticamente con toda la extensión que se habia ideado. La solución que se dio al resto del terreno, un espacio rectangular delimitado por la cerca de la Villa, el gran muro vertical contención de la tercera terraza y la fachada lateral del palacio, fue el utilizarlo, con el tiempo, como patio de comedias.

La puerta representativa de entrada al recinto palacial de la Villa, fue proyecta por Alonso de Covarrubias, esta vez en colaboración con Luis de Vega, que por esos mismos años, 1550, habían trazado la Puerta de la Bisagra en Toledo; fue otro de los elementos malogrados debido al pleito con el Concejo. Su diseño es desconocido, aunque podemos suponer que no sería en ningún caso una puerta de las características de la de Toledo, configurada con otras motivaciones. Esta puerta no se pudo realizar por lo costosa que resultaba, la pérdida de materiales, el retraso en las obras y lo costoso del propio pleito, aunque sí se mantuvo su emplazamiento original,

ellos tienen a cargo a facer la puerta del muro que sale a las/noguerillas en la calle de Boçeguillas en çierta forma/ e con çiertas condiciones en para ello tienen fechas obligacion/e agora no se ha de fazer conforme a la dicha traza no tan costosa/ puesto que se ha de fazer en el mismo lugar por cuanto que/ ellos dada por nynguna la dicha obligacion que tienen fecha $y /$ se obligan agora de fazer dicha portada delante e contorme que su señoria mande que se haga y que solamente llevaran puelaco en tasare Luys de Vega y que mereçe de se fazer/e Alonso de Covarrubias e que no quitaran mano de ella hasta que se acal bara e pena... ${ }^{23}$.

Todos los problemas provocados por el pleito, la paralización de las obras, la pérdida de materiales y, sobre todo, la irritación y el desánimo de Doña Ana, unido a los posteriores problemas con el convento de San 
Francisco ${ }^{24}$, determinaron que las obras se paralizasen totalmente, sin que nunca se llegase a terminar el propio palacio; como hemos indicado, nunca se llegó a construir el patio central, ni siquiera se inició, tampoco la escalera palacial que fue sustituida por una exterior y provisional, los jardines se realizaron sólo en parte, las torres traseras se malograron, el proyecto de la muralla se abandonó, y sobre todo, se abandonó la idea de realizar un conjunto.

En realidad, todos estos problemas dieron al traste con el propio proyecto de Señorío que habia propiciado la Condesa; su hijo Gastón de la Cerda vendió el Estado de Pastrana en cuanto le fue posible, pero previamente habia renunciado a la construcción de los símbolos del poder señorial en el mismo, paralizando las obras en cuanto fue posible.

Con ello podemos afirmar y resumir que el pleito interpuesto por el Concejo de Pastrana contra la Condesa de Mélito dio al traste con uno de los proyectos de conjunto más interesantes de los diseñados por Covarrubias. Aunque la obra de Pastrana se podría considerar como un encargo de rutina, Covarrubias no lo planteó como tal; es cierto que en el trazado del palacio siguió estrictamente el modelo, simplificado, de lo que estaba realizando para los Alcázares reales, pero la planta del mismo es un año anterior al toledano, con lo que estrictamente deberiamos considerar este último heredero del modelo del palacio de Pastrana. Pero la cuestión más importante no es si Pastrana es modelo del Alcázar de Toledo o no, sino si Covarrubias, en el más fructífero de sus períodos creativos, trasciende en Pastrana el planteamiento simple de un palacio señorial, para desarrollar por primera vez en el renacimiento español todo un complejo señorial perfectamente planificado, que como venimos apuntando estaba compuesto por diversos elementos y que, en líneas generales, como conjunto, quedó frustrado. Esta idea de conjunto palacial será retomada posteriormente en la Villa Ducal de Lerma, en el proyecto desarrollado por Francisco de Mora para Don Francisco Sandoval y Rojas, Duque de Lerma ${ }^{25}$.

\footnotetext{
24 A partir de 1553, se volvieron a vivir importantes problemas en la construcción, al iniciarse las obras de las torres traseras, que tuvieron que ser suspendidas por las quejas de los clérigos del convento de San Francisco, que alegaban que su construcción amenazaba sus cimientos, e in. cluso llegaron a poner un pleito contra la Condesa. E! resultado fue que las torres se quedaron sin construir. AHN (Archivo Histórico Nacional), Clero, legajo n. 2.024... Por una información hecha en esta villa de Pastrana en 25 de noviembre de 1553 ante el eso. de esta villa Alonso Brabo a instancia del sindico de esta Cmo sobre el perjuicio que se seguia en los cimientos de este con vento con motivo de sacar los de la casa y fortaleza que comenzó a edificar la llima $S .{ }^{a} \mathrm{D}$. Ana de la Cerda...

25 Cervera Vera, Luis: El conjunto palacial de la Villa de Lerma. Burgos, reed. 1996.
} 
A la muerte de Doña Ana el palacio se encuentra aún en plena construcción; ante él existía un gran espacio amurallado, a modo de amplia terraza sobre la vega del Arlés, recinto al que se accedía por la puerta proyectada originalmente por Covarrubias y Luis de Vega, construida como arco simétrico a la puerta de Zorita que más tarde será conocida como puerta del Albaicín. Dicho palacio y explanada quedaban totalmente desvinculados de la Villa debido a la separación que establecía la muralla reconstruida, a la cual se accedia por la antigua puerta medieval de Zorita. Puerta que no hubiera sido necesario si la cerca en esa parte no hubiera existido. Quizás esta nueva configuración de plaza limitada por dos cercas, la de la Villa y la de cerramiento del palacio ${ }^{26}$, fuera lo que permitió posteriormente a su nuevo señor, Ruy Gómez, disponer una plaza regular de mercado y realizar una serie de transformaciones urbanísticas que convirtieron a la Villa de Pastrana en uno de los enclaves en los que mejor se plasmarán las características urbanas del Renacimiento; el conjunto plaza-palacio se convirtió, en eje de unión entre la Villa medieval y el ensanche renacentista promovido por Ruy Gómez de Silva, que constará del barrio nuevo del Albaicín, barrio industrial, de trazado reticular a pesar de la topografía adversa, y la recta calle Ancha.

:6sta cerca sabemos que se empezó a construir. Existe un gran cubo en una de las esquinas de los Adarves, sin poder precisar si se realizó entera, es decir, si llegó a cerrar toda la plaza hasta la puerta y el palacio. 